\title{
FDA eCTD Terminology
}

National Cancer Institute

\section{Source}

National Cancer Institute. FDA eCTD Terminology. NCI Thesaurus. Code C97181.

Terminology developed to support the efforts of Electronic Common Technical

Documents. 